\title{
0 Segredo Ineficiente Revisto: 0 que Propõem e o que Aprovam os Deputados Brasileiros*
}

\author{
Octavio Amorim Neto \\ Fabiano Santos
}

\section{INTRODUÇÃO}

Q ue fatores induzem o comportamento dos legisladores nos sistemas presidencialistas latino-americanos? Com a consolidação da democracia, o comportamento dos parlamentares tornou-se um tema fundamental na literatura comparada sobre as instituições políticas da região (Carey e Shugart, 1998; Jones, 1995; Linz e Valenzuela, 1994; Mainwaring e Scully, 1995; Mainwaring e Shugart, 1997; Mor-

\footnotetext{
* Este texto é uma versão revista de um trabalho apresentado no 3 o Encontro da Associação Brasileira de Ciência Política - ABCP, realizado na Universidade Federal Fluminense - UFF, Niterói, RJ, em 28-31 de julho de 2002. A pesquisa em que se baseou o artigo foi financiada pelo Instituto Brasileiro de Economia - IBRE e pela Fundação de Amparo à Pesquisa do Estado do Rio de Janeiro - FAPERJ (no âmbito do Instituto Virtual "A Democracia e os Três Poderes no Brasil", coordenado pelo professor Luiz Werneck Vianna). Os autores agradecem a John Carey, Antônio Octávio Cintra, Argelina Figueiredo, Mona Lyne e Aníbal Pérez-Liñán pelos comentários a versões anteriores. Mônica Ribeiro Cardoso, Cléber de Deus, Juliana Estrella, Márcio Grijó, Alan Lacerda e Luiz Lourenço trabalharam como assistentes de pesquisa. Barry Ames e Timothy Power colocaram à nossa disposição seus dados eleitorais e biografias de congressistas, respectivamente. Este artigo foi publicado na Legislative Studies Quarterly, vol. XXVIII, no 4, 2003, pp. 449-479. Agradecemos ao editor da revista, professor Gerhard Loewenberg, pela autorização para publicar o texto em Dados. [A tradução do original em inglês "The Inefficient Secret Revisited: The Legislative Input and Output of Brazilian Deputies" é de Vera Pereira.]
}

DADOS - Revista de Ciências Sociais, Rio de Janeiro, Vol. 46, n-4 4, 2003, pp. 661 a 698. 
genstern e Nacif, 2002; Shugart e Carey, 1992). E dada a centralidade dos corpos representativos em regimes democráticos, não surpreende a multiplicação de estudos sobre o Legislativo na América Latina.

Uma das contribuições mais importantes para essa literatura é o modelo do segredo ineficiente, de Shugart e Carey (1992:167-205). O segredo ineficiente é obviamente o oposto do segredo eficiente de Cox (1987). Um sistema político dotado de um segredo eficiente é aquele em que os eleitores conseguem fazer uma clara opção acerca de políticas públicas nacionais entre partidos concorrentes. Essa escolha requer que os políticos eleitos pensem, na maioria das vezes, no alcance nacional de suas propostas legislativas e demonstrem alta disciplina partidária. O Reino Unido é o exemplo perfeito dessas condições. Em um sistema político movido pelo segredo ineficiente, os legisladores têm um foco paroquial de atuação parlamentar, o que significa dizer que, no período eleitoral, não oferecem aos eleitores opções claras a respeito de políticas públicas nacionais, e, além disso, a disciplina partidária é fraca. O segredo ineficiente decorre sobretudo da interação de dois fatores institucionais: um Executivo dotado de fortes poderes legislativos e líderes partidários com baixa capacidade de controle sobre seus liderados. Que tipos de dinâmicas políticas são gerados por esse desenho institucional?

Para entender a lógica do modelo do segredo ineficiente (doravante referido como MSI), é preciso examinar as origens de sua estrutura constitucional. O modelo pressupõe que os partidos nacionais são dominados por líderes locais, ou caciques, que, por sua vez, controlam uma assembléia constituinte. Os caciques demandam um sistema eleitoral que lhes preserve a autonomia local e um Executivo dotado de fortes poderes legislativos. Em outras palavras, querem proteger sua autonomia local ao mesmo tempo que se preocupam com a capacidade do governo de elaborar políticas públicas de abrangência nacional. Na qualidade de legisladores, eles agem como lobistas perante o Executivo federal buscando maximizar as transferências de recursos para suas clientelas e, dessa forma, especializam-se em canalizar para seus distritos eleitorais projetos e verbas federais. O paroquialismo dos caciques provoca um sério problema de coordenação quanto à sua capacidade de tomar decisões consistentes sobre políticas nacionais. Os caciques escapam a esse dilema recorrendo ao que Elster (1988:18) denomina de racionalidade estratégica, isto é, à solução de "dar um passo atrás e dois para a frente": delegam autoridade 
ao Executivo, de modo a limitar sua prodigalidade sobre o orçamento federal. Dado esse passo atrás, passam a concentrar esforços na provisão de bens privados às suas clientelas locais, sem se responsabilizarem pela gestão do governo federal ou correrem o risco de solapar completamente as políticas do Executivo (dois passos para a frente).

Note-se que o MSI implica uma divisão específica do trabalho legislativo - ou um padrão particular de apresentação de projetos e aprovação de leis - que se pode resumir em três proposições: (1) os congressistas apresentam projetos de lei de baixo impacto que beneficiam seus distritos eleitorais, enquanto o Executivo propõe projetos de impacto nacional; (2) diferentemente das propostas de iniciativa do Executivo, poucos projetos dos congressistas passam na Câmara, já que os legisladores não gastam tempo tentando aprová-los ${ }^{1}$; (3) os poucos projetos iniciados pelos deputados que são aprovados também têm baixo impacto e beneficiam igualmente suas regiões eleitorais. A ineficiência de tal divisão do trabalho legislativo reside no fato de o paroquialismo dos congressistas não oferecer aos eleitores opções claramente identificáveis entre políticas públicas nacionais na época das eleições. Além disso, o foco paroquial da atuação dos parlamentares induz a outra forma de ineficiência: a irresponsabilidade fiscal (Shugart e Carey, 1992:168-170). Neste artigo vamos nos ocupar apenas da ineficiência eleitoral.

Ao lado da Colômbia e do Chile de antes de 1958, o Brasil é um dos mais notáveis exemplos de segredo ineficiente. A Constituição de 1988 concede ao chefe do Executivo o mais vasto arsenal de prerrogativas legislativas entre os regimes presidencialistas puros do mundo. E, mais ainda, como afirmam Shugart e Carey (idem:177), a adoção do sistema de representação proporcional de lista aberta no Brasil colocou os líderes dos partidos brasileiros entre os mais fracos do ponto de vista da capacidade de controle eleitoral de seus liderados.

Dez anos já se passaram desde a publicação do livro de Shugart e Carey. Felizmente, surgiram nesse período numerosos e férteis estudos sobre política brasileira, os quais nos permitem avaliar a eficácia analítica do MSI.

Parece haver, principalmente, um amplo consenso entre os estudiosos da política brasileira de que as prerrogativas constitucionais concedem grande poder ao chefe do Executivo. Pelo que nos é dado sa- 
ber, ninguém alegou até hoje que os presidentes brasileiros tenham abdicado desses poderes. Portanto, o primeiro pilar do segredo ineficiente - a extensão dos poderes legislativos do presidente da República - parece ser empiricamente sólido.

O segundo pilar - o controle dos líderes sobre seus liderados - tem sido objeto de acalorado debate acadêmico. Examinando dados sobre votos individuais dos deputados, Ames (2001) conclui que os partidos brasileiros são realmente pouco disciplinados e que seus membros somente cooperam com o chefe do Executivo quando devidamente recompensados com dotações orçamentárias para suas clientelas. Utilizando índices agregados de comportamento partidário (o índice Rice), Mainwaring (1999) considera os partidos brasileiros, na melhor das hipóteses, como moderadamente disciplinados, e por isso somente oferecem ao governo um apoio instável. Baseando-se nos mesmos índices, Figueiredo e Limongi (1999; 2000; ver, também, Limongi e Figueiredo, 1995) afirmam que os partidos brasileiros têm um comportamento em plenário altamente previsível, e a principal conseqüência disso é que as maiorias tendem a se formar mediante acordos de coalizão entre o presidente e os líderes de partidos, e não entre o presidente e cada congressista em particular. Portanto, o segundo pilar do segredo ineficiente manifesta-se empiricamente de modo contraditório.

O que se pode dizer sobre a divisão do trabalho legislativo criada pelo segredo ineficiente? Quanto às duas primeiras proposições, a observação de Figueiredo e Limongi $(1999 ; 2000)$ de que $86 \%$ das leis sancionadas entre 1989 e 1998 foram de iniciativa do Poder Executivo certamente confirma o modelo. No que diz respeito à terceira proposição - o baixo impacto dos projetos de lei apresentados pelos deputados-, Limongi e Figueiredo (2001a; 2001b) e Samuels (2002) mostram que a maioria das emendas dos deputados às propostas orçamentárias do Executivo tem por alvo seus estados de origem, e não municípios ou regiões. Sabendo-se que no Brasil os estados funcionam como distritos nas eleições congressuais, essas conclusões acerca das emendas orçamentárias nos parecem, em princípio, perfeitamente compatíveis com o MSI.

Apesar disso, o desempenho empírico do MSI demanda um aprofundamento das pesquisas sobre o tema, principalmente porque ainda existem dúvidas em relação às motivações e ao comportamento dos 
legisladores brasileiros. Note-se que até hoje nenhum estudo examinou em profundidade o foco de uma atividade essencial dos deputados brasileiros - o processo de elaboração de leis. Por esse motivo, este artigo pretende contribuir para o conhecimento acumulado sobre a política parlamentar na América Latina em geral e no Brasil em particular, utilizando um modelo macropolítico que caracteriza os regimes políticos - o MSI-e submetendo-o a uma análise micropolítica do comportamento individual dos deputados brasileiros.

Nossos dados incluem todos os 269 projetos de lei apresentados por deputados e transformados em lei entre 1985 e 1999, bem como os 1.291 projetos de lei propostos em 1995. O estudo examina quem propôs o quê em 1995 e identifica os atributos dos deputados que conseguiram aprovar suas propostas no período de 1985 a 1999. Mostramos que, se o MSI acerta algumas conseqüências legislativas do sistema de representação proporcional de lista aberta, não esclarece o impacto de várias estratégias eleitorais de que se valem os deputados, como demonstra Ames (2001), nem as conseqüências da clivagem governo-oposição no comportamento parlamentar e na eficiência eleitoral.

O artigo está estruturado da seguinte maneira. A segunda seção examina o nível de agregação, o efeito e os assuntos das propostas dos deputados e das leis que eles a provam, usando uma tipologia criada por Taylor-Robinson e Diaz (1999). Os principais achados desse estudo são que a maior parte da produção legislativa dos deputados brasileiros tem abrangência nacional, traz mais benefícios do que impõe custos e trata de questões sociais. Usando uma análise logit, a terceira seção mostra que os deputados que mantêm laços de proximidade com os eleitores propõem leis de nível mais estreito de agregação e que os governistas tendem a apresentar menos projetos de alcance nacional do que os oposicionistas. Esta última observação sugere que há um certo partidarismo nos projetos apresentados pelos deputados. Em seguida, o artigo identifica os fatores que afetaram a capacidade dos deputados de obter a aprovação dos seus projetos no período 1985-1998. A análise logit sugere que os deputados formalmente ligados ao partido de sustentação do regime militar (1964-1985) tinham menos chances de conseguir aprovar seus projetos; além disso, demonstra que os políticos com carreiras parlamentares mais longas e que haviam exercido cargos de relevo na Câmara ou no Executivo tinham mais facilidade de aprovar seus projetos. Os dados sobre a produção legislativa sugerem que o partidarismo não tem nenhuma in- 
fluência nesse aspecto do processo decisório. A seção de conclusões contém uma revisão do MSI à luz de nossos principais resultados. Afirmamos que, em certas circunstâncias, uma dinâmica eleitoral mais eficiente pode emergir de um sistema baseado no segredo ineficiente. Sugerimos também que, para representar corretamente o comportamento parlamentar e o processo decisório nos regimes presidencialistas do Brasil e de outros países da América Latina, os analistas devem incluir em seus modelos supostos de natureza partidária e distributivista.

\section{CLASSIFICANDO PROJETOS E LEIS}

Para classificar os projetos apresentados pelos deputados brasileiros, adaptamos para uso no Brasil uma tipologia criada por Taylor-Robinson e Diaz (1999) para avaliar o processo legislativo em Honduras. Esta tipologia é útil para os propósitos deste estudo porque explora os níveis de agregação dos projetos e seus efeitos. Recorde-se que é possível deduzir do MSI que os deputados brasileiros tenderão a propor leis de baixo nível de agregação e que geram efeitos benéficos para suas clientelas eleitorais.

Quanto ao nível de agregação, Taylor-Robinson e Diaz definiram cinco categorias: individual, local, regional, setorial e nacional. Classificamos um projeto de lei como de nível individual de agregação quando tem como alvo um único ou uns poucos indivíduos; é o caso dos projetos honoríficos e dos que concedem pensão a viúvas de ex-presidentes. Um projeto de lei de nível local de agregação é aquele que tem por objeto um único município, ou um pequeno número deles, mas não a totalidade dos municípios de um estado, região ou país. Os projetos de nível de agregação regional visam a um ou a alguns estados ou regiões, mas não à totalidade das regiões do país. Classificamos um projeto como de nível setorial quando tem por objeto um determinado setor da economia ou ramo de atividade profissional - os melhores exemplos são os projetos de regulamentação do exercício de uma nova profissão. Finalmente, os projetos de nível nacional afetam indiscriminadamente todos os grupos de cidadãos, regiões, estados e municípios.

No entanto, há uma séria dificuldade na aplicação dos critérios de nível de agregação ao caso brasileiro. Se a finalidade de um projeto de lei que estabelece isenções fiscais é o desenvolvimento de uma região 
pobre, cujas condições representam um problema para o país inteiro (como foi o caso da Operação Nordeste, do presidente Juscelino Kubitschek, em 1956-1961), será correto classificá-lo em uma categoria mais estreita que a nacional? Ou, quando se trata de um projeto de lei destinado a impulsionar o desenvolvimento de áreas metropolitanas em regiões de nível de renda inferior a um determinado limite, será essa lei subnacional, em um sentido restritivo, ou estará relacionada a um problema de abrangência nacional? Na gestão de Fernando Henrique Cardoso (1995-2002), por exemplo, o governo federal desenvolveu um programa denominado Alvorada, cuja finalidade era ajudar municípios muito pobres concentrados em determinadas regiões do país. Seria correto classificar esse programa como não nacional, sabendo-se que estava em jogo um interesse geral? O Alvorada era um programa, não um projeto de lei, mas a essência da questão é a mesma. Ou seja, alguns projetos criam programas que parecem ter um nível de agregação restrito, ou não nacional, mas que, na realidade, têm por objetivo solucionar problemas nacionais ${ }^{2}$.

Não é nada fácil resolver essa limitação dos critérios de classificação. Uma possível solução seria tentar interpretar a intenção dos legisladores quando propõem projetos de lei. Contudo, esse exercício de interpretação acarreta necessariamente uma série de juízos subjetivos e ad hoc, o que prejudica, por definição, a objetividade dos critérios. Deve-se considerar ainda que programas como o Alvorada têm óbvio impacto e motivação política locais. Assim, dada a ambigüidade desses casos, preferimos correr o risco de um eventual erro de avaliação quanto ao nível de agregação de um projeto de lei a desistir de uma aplicação coerente e homogênea dos critérios.

Quanto aos efeitos dos projetos de lei, Taylor-Robinson e Diaz (idem:618-619) subdividiram essa variável em quatro categorias: benéfica, onerante, mista e neutra. Projetos benéficos são os que concedem benefícios a um indivíduo, uma prefeitura, uma região, um grupo social ou ao país como um todo. Projetos onerantes são os que impõem ônus financeiros ou regulatórios. Os projetos mistos são os que ao mesmo tempo beneficiam algumas pessoas e oneram outras, como, por exemplo, os que provêem proteção a uma bacia hidrográfica. Essa proteção gera efeitos mistos porque traz benefícios ecológicos, mas impõe custos a agricultores e indústrias locais. Os projetos neutros comemoram um acontecimento específico, estabelecem um 
dia de festa sem conceder um feriado aos trabalhadores, ou especificam um contrato já existente sem ajudar ou prejudicar as pessoas.

Além dos efeitos citados, acrescentamos uma terceira variável à classificação de Taylor-Robinson e Diaz: o assunto ou objeto dos projetos de lei. Criamos oito categorias: administrativa, econômica, honorífica, orçamentária, política, social, cultural-científica-tecnológica e ecológica. Geralmente é fácil identificar o assunto de um projeto de lei pelo sumário e palavras-chave fornecidos pelo Centro de Informática e Processamento de Dados do Senado Federal - PRODASEN. Mas quando um projeto trata de vários assuntos, a solução foi avaliar o tópico mais proeminente.

As Tabelas 1, 2 e 3 mostram o nível de agregação, o efeito e o assunto dos projetos convertidos em lei no período de 1985 a 1999. Para nossa surpresa, descobrimos que dois terços das 269 leis têm nível nacional de agregação. Mas não nos surpreendeu que quase a metade das leis seja benéfica e somente 6,3\% delas, a menor fração, sejam onerantes. É interessante notar que cerca de metade dos projetos de iniciativa de deputados transformados em lei trata de uma temática social. Não houve leis orçamentárias, mas isto se explica pelo fato de que esse tipo de projeto só é examinado pela Câmara quando encaminhado pelo Poder Executivo. Matérias de natureza política e econômica também são áreas importantes no trabalho legislativo dos deputados. Contudo, o número de leis que tratam dessas matérias é significativamente menor do que o das referentes a questões sociais.

Tabela 1

Nível de Agregação da Produção

Legislativa dos Deputados

(1985-1999)

\begin{tabular}{l|c|c}
\hline Nível & $\mathbf{N}$ & $\mathbf{\%}$ \\
\hline Individual & 12 & 4,5 \\
Local & 23 & 8,6 \\
Regional & 5 & 1,9 \\
Setorial & 50 & 18,6 \\
Nacional & 179 & 66,5 \\
\hline Total & $\mathbf{2 6 9}$ & $\mathbf{1 0 0 , 0}$ \\
\hline
\end{tabular}

Fontes: Brasil. Senado Federal (2000) e dados do Prodasen. 
Tabela 2

Efeitos da Produção Legislativa dos

Deputados

(1985-1999)

\begin{tabular}{l|c|c}
\hline Efeito & N & \% \\
\hline Benéfico & 132 & 49,1 \\
Onerante & 17 & 6,3 \\
Misto & 57 & 21,2 \\
Neutro & 63 & 23,4 \\
\hline Total & $\mathbf{2 6 9}$ & $\mathbf{1 0 0 , 0}$ \\
\hline
\end{tabular}

Fontes: Brasil. Senado Federal (2000) e dados do PRODASEN.

Tabela 3

Assuntos da Produção Legislativa dos Deputados (1985-1999)

\begin{tabular}{l|c|c}
\hline Assunto & N & \% \\
\hline Administrativo & 21 & 7,8 \\
Econômico & 62 & 23,0 \\
Honorífico & 15 & 5,6 \\
Orçamentário & 0 & 0,0 \\
Político & 30 & 11,2 \\
Social & 129 & 48,0 \\
Cultural-Científico-Tecnológico & 4 & 1,5 \\
Ecológico & 8 & 3,0 \\
\hline Total & $\mathbf{2 6 9}$ & $\mathbf{1 0 0 , 0}$ \\
\hline
\end{tabular}

Fontes: Brasil. Senado Federal (2000) e dados do ProdasEn.

A Tabela 4 apresenta o número e a porcentagem de leis por partido. $\mathrm{O}$ que nos revelam esses dados? Aparentemente, os autores do maior número de leis pertencem aos maiores partidos. Em primeiro lugar está o PMDB, seguido pelo PSDB, PFL, PT, PDS e PPB. Observe-se que outros dez micropartidos conquistaram umas poucas cadeiras na Câ- 
Tabela 4

Produção Legislativa dos Deputados

por Partido

(1985-1999)

\begin{tabular}{l|c|c}
\hline \multirow{2}{*}{ Partido } & \multicolumn{2}{|c}{ Total } \\
\cline { 2 - 3 } & N & \% \\
\hline PDS & 23 & 8,6 \\
PMDB & 82 & 30,5 \\
PFL & 32 & 11,9 \\
PDT & 16 & 5,9 \\
PSDB & 39 & 14,5 \\
PCB & 2 & 0,7 \\
PTB & 11 & 4,1 \\
PT & 26 & 9,7 \\
PC do B & 2 & 0,7 \\
PRN & 5 & 1,9 \\
PPR & 3 & 1,1 \\
PPB & 18 & 6,7 \\
PSB & 3 & 1,1 \\
PJ & 1 & 0,4 \\
PDC & 2 & 0,7 \\
PL & 4 & 1,5 \\
PPS & 0 & 0,0 \\
\hline Total & $\mathbf{2 6 9}$ & $\mathbf{1 0 0 , 0}$ \\
\hline
\end{tabular}

Fontes: Brasil. Senado Federal (2000) e dados do Prodasen.

mara Federal no período de 1985 a 1999, mas jamais conseguiram aprovar uma única lei. Significativamente, há uma relação linear quase perfeita entre a autoria de leis por partido e o peso parlamentar médio dos partidos nesse período. Fazendo a regressão da primeira variável sobre a segunda, obtemos a seguinte equação:

Produção $=0,023+0,997$ (tamanho do partido)

$$
\left(\mathrm{N}=27 ; \mathrm{R}^{2} \text { ajustado }=0,865\right)
$$

O fato de a relação entre a porcentagem média de cadeiras controladas por um partido e a porcentagem de leis de autoria de seus membros ser de paridade quase perfeita indica que os partidos não afetam 
a produção legislativa da Câmara Baixa; se afetassem, a relação não seria linear - isto é, os pequenos partidos dificilmente conseguiriam aprovar seus projetos ou os grandes partidos, sobretudo os que habitualmente aderem à coalizão governativa (em geral, o PMDB, o PFL e o PSDB), conseguiriam aprovar os deles a taxas superiores ao peso que têm na Câmara ${ }^{3}$. Na realidade, conforme se verá mais à frente, $\mathrm{o}$ conteúdo das leis patrocinadas por deputados não tem nada a ver com as clivagens clássicas que opõem os partidos políticos, e certos atributos dos deputados explicam sua capacidade de obter a aprovação e a transformação em lei dos seus projetos.

Procuramos também verificar se os partidos se especializam em algum nível de agregação, efeito ou temática (os dados não estão relatados neste artigo). Quanto ao assunto, os integrantes do PT, PFL e PSDB concentram cerca de metade de sua produção legislativa em leis de natureza social, mas a produção dos peemedebistas distribui-se de forma eqüitativa entre os diversos assuntos. Os deputados do PPB não se concentram na elaboração de leis sociais. No que se refere ao nível de agregação e aos efeitos, não se observa uma variação muito significativa entre os partidos: todos concentram esforços em leis que geram benefícios de abrangência nacional. Este dado parece corroborar a idéia implícita no MSI de que os partidos brasileiros não diferem muito do ponto de vista da produção de políticas públicas. Veremos, porém, na próxima seção que existem, sim, importantes diferenças entre governo e oposição no que se refere ao conteúdo dos projetos de lei apresentados.

Neste ponto, a questão que se impõe é a seguinte: como se explica o predomínio de leis do tipo nacional, benéfico e de teor social? Acreditamos que a resposta a esta pergunta depende dos efeitos da concentração dos poderes de agenda nas mãos do Executivo e de suas conseqüências no comportamento dos deputados. Para elaborar tal resposta, recorremos ao caso inglês como ponto de referência comparativo. A comparação talvez pareça despropositada, já que a Inglaterra é o principal exemplo de sistema político movido por um segredo eficiente. Contudo, a Inglaterra, tal como o Brasil, tem um sistema político em que o poder decisório está concentrado no Executivo (Lijphart, 1999) e os membros do Legislativo têm um papel de menor importância no processo legislatório (Cox, 1987). Pelos mesmos motivos, a Inglaterra é uma boa ilustração do tipo de agenda que formulam os 
parlamentares, quando delegam ao Executivo prerrogativas decisórias a pretexto da eficiência.

Desde a segunda metade do século XIX, as regras de procedimento do Parlamento inglês vêm se modificando gradualmente de modo a ampliar o tempo dedicado às discussões em plenário dos projetos iniciados pelo gabinete e reduzir o tempo alocado aos backbenchers ${ }^{*}$ (idem:45-67). Os projetos de autoria de private members ${ }^{* *}$ eram considerados de alcance estritamente local e destinados a clientelas limitadas, ao contrário das propostas do governo que priorizavam as grandes questões nacionais. Pode-se dizer que, desde então, a agenda do gabinete tornou-se não só predominante, mas também eminentemente programática. Como observou Cox (idem), o gabinete começou a concentrar esforços em matérias que afetam o conjunto do país. Ao mesmo tempo, aspectos cotidianos dos problemas que afligem os cidadãos deixaram de ser mencionados especificamente na legislação.

A história recente da Inglaterra corrobora empiricamente essas afirmações. Durante as décadas de 60 e 70, foi sancionada uma série de leis referentes a uma diversidade de questões pós-modernas (permissão do aborto, divórcio, regulamentação sobre material pornográfico, entre outras). Essas leis tinham as seguintes características: haviam sido propostas por backbenchers e o gabinete não se envolveu diretamente na tramitação de nenhuma delas. Cabe notar que, desde o fim da Segunda Guerra Mundial até os anos 80, somente foram aprovados projetos de lei elaborados por private members em 24 ocasiões (Marsh e Read, 1988). O que isto significa?

Significa que nas raras oportunidades que os private members tiveram para propor leis e aprová-las, os projetos destinavam-se a tentar resolver problemas que não dividiam os partidos segundo linhas convencionais. $E$ foi exatamente por isso que o gabinete não se envolveu naquelas questões ${ }^{4}$. Nosso argumento é que a mesma coisa está acontecendo agora no Brasil. A concentração dos poderes de agenda nas mãos do Poder Executivo faz com que os projetos sociais iniciados pelo governo assumam um caráter mais agregado ou abstrato e ape-

\footnotetext{
*Backbenchers, originalmente, são os membros da Câmara dos Comuns que não são líderes de partido. [N. do T.]

**Private members são os membros do Parlamento que não ocupam cargos no gabinete. [N. do T.]
} 
nas toquem indiretamente em pormenores dos problemas que afetam cotidianamente os cidadãos. Os projetos de autoria dos deputados federais procuram preencher essa lacuna. Não admira, portanto, que os assuntos das 129 leis sociais promulgadas entre 1985 e 1999 fossem os seguintes: proibir as empresas de obrigarem os candidatos a um emprego a exibir atestado de esterilidade ou gravidez; substituição progressiva de produtos contendo asbesto; obrigatoriedade de prestar informações mensais sobre juros pagos pelos consumidores; regulamentação das vendas a prazo; definição do que são relações estáveis entre homem e mulher; distribuição gratuita de medicamentos a pessoas portadoras do vírus do HIV; obrigatoriedade de incluir dispositivos de segurança em seringas descartáveis para impedir sua reutilização; obrigatoriedade de editar publicações em braile; isenção de impostos para a aquisição de automóveis por deficientes físicos e regulamentação da doação de órgãos humanos.

Note-se que a legislação patrocinada por deputados federais não modifica o status quo em áreas relevantes como a macroeconomia ou as políticas fiscal e tributária. Isto quer dizer que a agenda legislativa dos deputados não promove programas de políticas públicas de largo alcance, como supõe o MSI. Ao contrário, os legisladores tendem a concentrar-se em alguns problemas tópicos que dizem respeito à vida cotidiana do cidadão médio. Em contraposição, eis uma lista das questões abordadas por alguns projetos recentes de iniciativa do Executivo: sistema de aposentadoria rural; reforma da legislação trabalhista; criação de um fundo social de emergência e determinação de regras de responsabilidade fiscal para todos os níveis de governo. Todos esses projetos têm um considerável impacto redistributivo.

Uma possível objeção a esses argumentos é que os projetos apresentados, e não as leis sancionadas, devem constituir a amostra para a avaliação das motivações dos congressistas no trabalho legislativo. Por isso, resolvemos examinar todos os projetos de lei levados à Câmara pelos deputados brasileiros em 1995. Escolhemos este ano porque foi o primeiro, após a promulgação da Constituição de 1988, em que o país não esteve às voltas com crises políticas ou econômicas. Ou seja, 1995 foi o primeiro ano de "normalidade" política, por assim dizer, no Brasil pós-autoritário. As Tabelas 5, 6 e 7 mostram o nível de agregação, os efeitos e os temas dos projetos de lei apresentados pelos deputados federais em 1995, respectivamente. 
Tabela 5

Nível de Agregação da Produção

Legislativa dos Deputados.

Projetos de Lei Apresentados em 1995

\begin{tabular}{l|c|c}
\hline Nível & $\mathbf{N}$ & $\mathbf{\%}$ \\
\hline Individual & 46 & 3,6 \\
Local & 54 & 4,2 \\
Regional & 28 & 2,2 \\
Setorial & 228 & 17,7 \\
Nacional & 935 & 72,4 \\
\hline Total & $\mathbf{1 . 2 9 1}$ & $\mathbf{1 0 0 , 0}$ \\
\hline
\end{tabular}

Fontes: Brasil. Senado Federal (2000) e dados do PRODASEN.

Tabela 6

Efeito dos Projetos Propostos pelos Deputados Federais em 1995

\begin{tabular}{l|c|c}
\hline Efeito & $\mathbf{N}$ & $\mathbf{\%}$ \\
\hline Benéfico & 717 & 55,5 \\
Onerante & 57 & 4,4 \\
Misto & 415 & 32,1 \\
Neutro & 102 & 7,9 \\
\hline Total & $\mathbf{1 . 2 9 1}$ & $\mathbf{1 0 0 , 0}$ \\
\hline
\end{tabular}

Fontes: Brasil. Senado Federal (2000) e dados do PRODASEN.

Tabela 7

Assunto dos Projetos Propostos pelos Deputados Federais em 1995

\begin{tabular}{l|c|c}
\hline Assunto & $\mathbf{N}$ & $\mathbf{\%}$ \\
\hline Administrativo & 63 & 4,9 \\
Econômico & 306 & 23,7 \\
Honorífico & 35 & 2,7 \\
Orçamentário & 3 & 0,2 \\
Político & 70 & 5,4 \\
Social & 737 & 57,1 \\
Cultural-Científico-Tecnológico & 42 & 3,3 \\
Ecológico & 35 & 2,7 \\
\hline Total & $\mathbf{1 . 2 9 1}$ & $\mathbf{1 0 0 , 0}$ \\
\hline
\end{tabular}

Fontes: Brasil. Senado Federal (2000) e dados do Prodasen. 
É significativo que a distribuição dos projetos de lei siga o mesmo padrão que observamos no caso das leis efetivamente sancionadas: $72,4 \%$ dos projetos têm um nível nacional de agregação (contra 66,5\% das leis); $55,5 \%$ deles geram um efeito benéfico ( $49,1 \%$ no caso das leis promulgadas); $57,1 \%$ tratam de questões sociais (contra $48,0 \%$ das leis sancionadas). Portanto, é possível afirmar com segurança que o conteúdo das leis sancionadas de autoria dos deputados constitui uma proxy confiável do conteúdo dos projetos de lei.

Resta examinar a razão do predomínio de leis de abrangência nacional na produção legislativa dos deputados federais brasileiros. Cabe recordar que essas leis não promovem amplos programas de política social e, por isso mesmo, não alteram o persistente status quo perverso do país; visam aos cidadãos em geral e não a áreas geográficas específicas. Em outras palavras, o paroquialismo dos deputados não se reflete em sua produção legislativa. Por quê?

Lemos (2001:576-577) chama a atenção para o fato de que o poder do Congresso para propor leis de natureza orçamentária e fiscal é muito limitado. Essas são áreas cruciais de políticas públicas em que é fácil beneficiar regiões e clientelas específicas. Isto é, os deputados não podem propor leis benéficas com um nível local de agregação porque poderosas barreiras constitucionais os impedem de fazê-lo. Por surpreendente que pareça, a incapacidade dos políticos brasileiros em aprovar leis paroquiais e benéficas é mais uma indicação de que o desenho institucional do país é regido por um segredo ineficiente. De acordo com o MSI, a prerrogativa de propor medidas de política econômica é delegada ao Poder Executivo. Em conseqüência disso, nas áreas de política pública em que os deputados têm liberdade para legislar há poucas oportunidades de obter verbas e projetos federais de interesse localizado.

Para os deputados federais, a principal oportunidade de obter verbas públicas para suas regiões é o processo orçamentário. Ames (1995; 2001) afirmou que os deputados geralmente fazem uso do seu direito de propor emendas ao orçamento, mas não temos informação alguma sobre a proporção do tempo que eles dedicam a essa tarefa em comparação com a que devotam a outras atividades essenciais, tais como legislar ou fazer lobby no Executivo. Não temos como aquilatar, pelos dados aqui apresentados, a importância relativa do trabalho dedicado à elaboração de emendas orçamentárias que envolvem gastos em 
comparação com o tempo devotado à apresentação de projetos que não implicam despesas públicas. Tudo o que nossos dados permitem afirmar é que o achado de que a maior parte da produção legislativa dos deputados não tem alcance estadual ou local não contradiz necessariamente o MSI. Esse fato é uma conseqüência direta das barreiras constitucionais que impedem os deputados de propor projetos, transferindo recursos orçamentários para regiões ou clientelas reduzidas. Essas barreiras representam, além disso, o "passo atrás" subjacente a uma estrutura institucional baseada no segredo ineficiente. Assim, os deputados são induzidos a concentrar suas atividades legislativas em questões tópicas de política social de abrangência nacional.

\section{QUEM PROPÕE O QUÊ NA CÂMARA DOS DEPUTADOS?}

Os dados analisados na seção anterior mostram que embora o MSI seja capaz de explicar boa parte da dinâmica institucional do Brasil, a capacidade explicativa do modelo quanto ao conteúdo da produção legislativa é bastante limitada. O objetivo desta seção é reformular o MSI de um modo que nos permita obter uma melhor compreensão das motivações subjacentes às iniciativas dos deputados.

Cabe lembrar, de início, que um pressuposto do MSI é que a estratégia eleitoral de equilíbrio no Brasil é cultivar o voto pessoal, o que traz como conseqüência uma conduta parlamentar paroquialista. Outro pressuposto do modelo é que esse tipo de incentivo influi de modo uniforme sobre todos os membros da Câmara Baixa. Mas em um estudo recente Ames (2001) questiona essa suposição.

Antes de nos aprofundarmos no trabalho de Ames, é conveniente dar uma breve explicação sobre o sistema eleitoral brasileiro. O país adota o sistema de representação proporcional de lista aberta nas eleições para a Câmara Baixa. Por ser uma federação, a disposição geográfica dos distritos eleitorais em pleitos para a Câmara dos Deputados justapõe-se à dos estados da federação. O número de cadeiras disputadas em cada distrito varia com o tamanho da população. O tamanho do distrito varia de um mínimo constitucional de oito cadeiras nos estados menores a um máximo de setenta para São Paulo, o maior eleitorado do país. Os eleitores dão apenas um voto para um candidato em uma lista partidária ou para a legenda de um partido. A posição do candidato na lista depende do número de votos que ele recebeu, o que estimula a competição entre candidatos do mesmo partido. Dado 
que a sorte eleitoral dos candidatos depende de sua capacidade de conquistar votos, presume-se que a melhor estratégia eleitoral para eles é cultivar o voto pessoal e conquistar eleitorados estreitos (Carey e Shugart, 1995).

Ames demonstra que embora os candidatos à Câmara Federal busquem atrair votos em todas as regiões dos seus estados, certas estruturas geográficas, sociais e econômicas, determinados padrões de carreira e a própria história favorecem diferentes tipos de estratégias de campanha, as quais, por sua vez, geram diversos padrões espaciais de distribuição de votos. Esses padrões são explicados por duas dimensões: a contigüidade espacial dos municípios em que o candidato recebe votos e o grau de dominância que ele tem nos municípios em que é votado. Um candidato tem uma distribuição dominante quando os votos que recebe saem de municípios onde ele obtém a maioria da totalidade dos votos dados. Uma distribuição compartilhada significa que o candidato é votado em municípios onde divide a totalidade da votação com outros concorrentes. A combinação dessas duas dimensões dá origem a quatro padrões de distribuição de votos: (1) distribuição dispersa de votos em municípios-chave combinada com uma baixa porcentagem da totalidade dos votos nesses municípios (tipo disperso-compartilhado); (2) distribuição dispersa dos votos combinada com uma alta porcentagem da totalidade da votação desses municípios (tipo disperso-dominante); (3) distribuição concentrada de votos combinada com uma baixa porcentagem da totalidade da votação (tipo concentrado-compartilhado); e (4) distribuição concentrada de votos combinada com uma porcentagem elevada da totalidade da votação dos municípios (tipo concentrado-dominante).

A análise de Ames indica que somente os deputados cujo padrão de distribuição de votos é do tipo concentrado ou dominante se empenham nos tipos de trocas paroquiais ou clientelistas com os eleitores que o MSI pressupõe. Esses políticos mantêm relações mais estreitas com o eleitorado e, por isso, são os únicos que têm a capacidade de reivindicar o crédito exclusivo pelos recursos federais que trazem para seus estados ou pelos serviços que proporcionam aos seus distritos eleitorais. Se essa análise for verdadeira, temos condições de especificar algumas das principais implicações do MSI, formulando duas hipóteses: 
Hipótese 1a. Quanto mais concentrado ou dominante for o padrão espacial de distribuição da votação de um deputado, maior será a probabilidade de que ele patrocine projetos de lei do tipo paroquial-benéfico.

Inversamente, também podemos afirmar que:

Hipótese 1b. Quanto mais concentrado ou dominante for o padrão espacial de distribuição dos votos de um deputado, menor será a probabilidade de que ele patrocine projetos de lei de nível nacional.

Considere-se ainda que o MSI somente reconhece os incentivos eleitorais criados pelo sistema de representação proporcional de lista aberta. Isto significa que o modelo ignora outras duas motivações fundamentais para o comportamento dos políticos: os objetivos programáticos e a busca de cargos (Strøm, 1990; Müller e Strøm, 1999). É justo esperar que essas motivações tenham um efeito na proposição de leis pelos deputados brasileiros.

Quanto à busca de cargos, afirmamos na Introdução que o MSI pressupõe que os deputados delegam a decisão de políticas de abrangência nacional ao Executivo por razões de eficiência. Novamente, o modelo presume que o incentivo para delegar ao Executivo se distribui uniformemente entre todos os membros da Câmara Baixa. Essa suposição é válida? Parece que não. Somente os deputados que fazem parte da coalizão parlamentar do governo têm motivos fortes para delegar as decisões de políticas nacionais ao Executivo, porque isto lhes permite dedicar seu tempo à negociação de verbas e recursos federais para suas regiões ou à prestação de serviços às suas clientelas. Os deputados da oposição têm motivos para propor projetos de alcance nacional, já que isto lhes permite marcar uma posição política perante os eleitores. Esse raciocínio nos leva à seguinte hipótese:

Hipótese 2. Os deputados que pertencem à coalizão parlamentar do presidente estão negativamente associados com o patrocínio de projetos de lei de alcance nacional.

E quanto às preocupações programáticas dos deputados? Vimos na seção anterior que não há muita diferença de conteúdo entre os projetos de lei propostos pelos deputados brasileiros e os que são finalmente transformados em lei. Contudo, a ideologia dos deputados pode influir no nível de agregação dos seus projetos. Essa hipótese se fundamenta em um recente estudo de Timothy Power (2000). De acor- 
do com Power, os padrões de recrutamento e de socialização política que prevaleceram durante o regime militar (1964-1985) criaram sérias distorções no comportamento dos parlamentares brasileiros durante o regime democrático instalado em 1985, principalmente no que diz respeito aos políticos que eram ou tinham sido filiados à extinta Arena/PDS.

Quais eram os padrões de recrutamento e socialização política durante o regime militar? Cabe lembrar, antes de tudo, que os poderes do Congresso tinham sido consideravelmente reduzidos em proveito do Executivo, o que tornou menos atraente fazer uma carreira parlamentar. Mas os políticos que permaneceram no Congresso tiveram de envolver-se em outras atividades não monopolizadas pelo Executivo, e já que havia poucas opções, a maioria optou pelo clientelismo. Power (idem:19) observa que

“[...] os incentivos para o clientelismo individualista não tiveram um efeito uniforme em toda a classe política. Os estímulos clientelistas foram mais fortes entre os políticos que apoiavam os militares e se beneficiavam com o acesso privilegiado aos recursos do Estado, e mais fracos entre aqueles que - excluídos dos círculos imediatos do poder e da patronagem - empenhavam todas as energias no ativismo oposicionista".

O resultado foi que os políticos socializados na patronagem e sob a influência de instituições parlamentares débeis tenderam - sob o novo regime democrático - a resistir ao fortalecimento do Congresso, temendo as pressões cada vez mais fortes para aumentar a prestação de contas aos eleitores pelos parlamentares, bem como a perda de espaço para o exercício do clientelismo. Três pesquisas de opinião realizadas por Power entre membros do Congresso em 1990, 1993 e 1995 revelaram que os antigos filiados da Arena / PDS davam menos apoio às medidas destinadas a fortalecer e institucionalizar os partidos que outros setores políticos (idem:124-139); eram menos atuantes nas atividades parlamentares clássicas; estavam menos interessados na função de representar grupos e mais envolvidos em interações clientelistas com a máquina do Estado (idem:166-170). Se Power estiver certo, temos razões para supor que o clientelismo dos antigos membros da Arena/PDS influa nos tipos de projetos que eles propõem. Portanto: 
Hipótese 3a. Os deputados que eram ou tinham sido filiados à Arena/PDS têm mais probabilidade de propor leis do tipo paroquial-benéfico do que os demais parlamentares.

Inversamente:

Hipótese 3b. Os deputados que eram ou tinham sido filiados à Arena/PDS têm menos probabilidade de propor leis de nível nacional do que os demais parlamentares.

A seguir, examinamos separadamente os dois tipos de hipóteses "a" e os três tipos de hipóteses " $\mathrm{b}$ ", utilizando uma análise logit.

\section{As Hipóteses do Tipo "a"}

A variável dependente para as hipóteses do tipo "a" é uma variável binária que explora se um deputado eleito em 1994 propôs em 1995 pelo menos um projeto de lei com nível de agregação individual ou local. As medidas de concentração e dominância foram fornecidas por Ames. A afiliação prévia à Arena/PDS também é medida por uma variável binária. Atribuímos o valor 1 a um deputado que fosse ou tivesse sido filiado à Arena/PDS e o valor zero à situação oposta ${ }^{5}$.

Tabela 8

Estimativas Logit sobre a Apresentação pelos

Deputados Federais de Projetos Paroquiais - 1995

(erros padrões entre parênteses)

Equações de cálculo da probabilidade de um deputado propor pelo menos um projeto de lei de tipo paroquial em 1995

\begin{tabular}{l|ccc}
\hline \multirow{2}{*}{ Variáveis Independentes } & \multicolumn{3}{|c}{ Modelos } \\
\cline { 2 - 4 } Constante & $\mathbf{1}$ & $\mathbf{2}$ & $\mathbf{3}$ \\
& $-2,700^{* * *}$ & $-2,790^{* * *}$ & $-3,047^{* * *}$ \\
Concentração & $(, 427)$ & $(, 416)$ & $(, 332)$ \\
&, $006^{* *}$ &, $006^{* *}$ &, $006^{* *}$ \\
Dominância & $(, 003)$ & $(, 003)$ & $(, 003)$ \\
& $-1,600$ & $-1,692$ & \\
Afiliação à Arena/PDS & $(1,794)$ & $(1,775)$ & \\
&,- 228 & & $-98,643$ \\
Log da probabilidade & $(, 522)$ & & 389 \\
№ de observações & $-97,285$ & $-98,178$ & 389 \\
\hline
\end{tabular}

*** $\rho<0,01 ;{ }^{* *} \mathrm{p}<0,05 ; * \rho<0,1$. 
A Tabela 8 apresenta os resultados das regressões. No modelo 1 , somente a concentração se mostrou significante (no nível de 0,05 ) e veio com o sinal positivo esperado. A variável Arena/PDS exibiu um resultado estatisticamente não significante, provavelmente porque em 1995 o número dos antigos membros desses partidos fosse menor do que nas legislaturas anteriores. A variável afiliação à Arena/PDS também é colinear com a concentração e a dominância. Por essa razão, eliminamos a afiliação a esse partido no teste do modelo 2 . Neste modelo, somente a concentração apareceu com o sinal correto e revelou um efeito significante sobre a variável dependente (no nível de 0,05). Finalmente, o modelo 3 representa uma equação de regressão bivariada em que a única variável independente é a concentração, que manteve o sinal, o coeficiente e o nível de significância $(0,05)$ encontrados nos modelos anteriores. Em termos substantivos, os coeficientes encontrados no modelo 3 indicam que um deputado cujos votos tinham uma concentração geográfica máxima tem uma probabilidade de 20,6\% de propor um projeto de lei destinado a beneficiar seu eleitorado, em comparação com a probabilidade de 4,2\% de um deputado cujos votos se distribuem geograficamente com um grau máximo de dispersão tomar a mesma iniciativa. A diferença é considerável $^{6}$.

Observe-se, porém, que somente 28 dos 389 deputados que compõem a amostra apresentaram, em 1995, pelo menos um projeto de lei do tipo paroquial-benéfico. Isto indica que um suposto fundamental do MSI - que os deputados concentram suas atividades no trabalho em favor de clientelas pequenas - é um fenômeno muito limitado no que concerne a iniciativas legislativas.

\section{As Hipóteses do Tipo “b” e a Hipótese 2}

Aqui, a variável dependente também é binária e explora se cada deputado eleito em 1994 apresentou, em 1995, pelo menos um projeto de lei de nível nacional de agregação. Recorde-se que agora, além das três variáveis explicativas examinadas nos modelos 1, 2 e 3, também verificamos o efeito das relações dos deputados com o Executivo em suas iniciativas legislativas. Visto que as nomeações para o Ministério são consideradas a principal arma do chefe do Executivo para a construção de uma base de apoio parlamentar no Brasil (Ames, 2001; Amorim Neto, 2002; Figueiredo e Limongi, 1999; 2000), a nova variável é estimada como uma variável binária que atribui o valor 1 aos de- 
putados filiados a partidos representados no Ministério e o valor zero na situação contrária ${ }^{7}$.

Tabela 9

Estimativas Logit sobre a Apresentação pelos Deputados Federais de Projetos de Lei de Impacto Nacional - 1995 (erros padrões entre parênteses)

As equações estimam a probabilidade de um deputado propor pelo menos um projeto de lei de nível nacional em 1995

\begin{tabular}{l|ccc}
\hline \multirow{2}{*}{ Variáveis Independentes } & \multicolumn{3}{|c}{ Modelos } \\
\cline { 2 - 4 } Constante & $\mathbf{4}$ & $\mathbf{5}$ & $\mathbf{6}$ \\
\hline \multirow{3}{*}{ Concentração } &, $941^{* * *}$ &, $901^{* * *}$ & $1,168^{* * *}$ \\
& $(, 258)$ & $(, 250)$ & $(, 224)$ \\
Dominância &, $003^{* *}$ &, $004^{* *}$ & \\
& $(, 002)$ & $(, 002)$ & \\
Partidários do presidente & $-3,348^{* * *}$ & $-3,522^{* * *}$ & $-3,315^{* * *}$ \\
& $(, 968)$ & $(, 947)$ & $(, 937)$ \\
Afiliação à Arena/PDS &,$- 624^{* * *}$ &,$- 604^{* * *}$ &,$- 610^{* * *}$ \\
& $(, 223)$ & $(, 219)$ & $(, 217)$ \\
Log da probabilidade &,- 126 & & \\
№ de observações & $(, 255)$ & & $-254,418$ \\
\hline
\end{tabular}

*** $\rho<0,01 ; * * \rho<0,05 ; * \rho<0,1$

Os resultados apresentados na Tabela 9 indicam que no modelo 4 todas as variáveis explicativas, exceto a afiliação à Arena/PDS, se mostraram significantes em um bom nível de significância. Entretanto, a concentração veio com o sinal errado. Esperávamos que essa variável tivesse um efeito negativo na proposição de leis de nível nacional. Testamos um quinto modelo, excluindo a filiação à Arena/PDS, e os resultados foram qualitativamente semelhantes aos do modelo 4 . No modelo 6, eliminamos a variável concentração e, mais uma vez, encontramos os mesmos resultados: a dominância e o pertencimento à coalizão parlamentar do presidente tiveram o impacto negativo esperado sobre a iniciativa dos deputados de proporem projetos de lei de abrangência nacional, ambos com níveis de significância de 0,01. Fixando na média a participação na coalizão parlamentar do governo, um deputado que possui dominância máxima nos municípios onde é votado registra uma probabilidade de $31,7 \%$ de propor um projeto de 
lei de alcance nacional, enquanto um outro que tem uma taxa de compartilhamento máximo da votação em seus municípios-chave registra $69,4 \%$ de chances de apresentar à Câmara um projeto do mesmo tipo - a diferença é enorme. De modo análogo, fixando a dominância na média, um deputado que apóia o governo tem uma probabilidade de $49,4 \%$ de apresentar um projeto de abrangência nacional, contra $64,3 \%$ de chances de um parlamentar da oposição; isto é, uma chance aproximadamente $30 \%$ maior que a do governista ${ }^{8}$.

Em resumo, os resultados estatísticos desta pesquisa sugerem que, por manterem relações mais estreitas com o eleitorado, os deputados dominantes preocupam-se menos com a elaboração de políticas de impacto nacional do que os parlamentares que dividem suas bases eleitorais com outros políticos. O incentivo para delegar ao Executivo a elaboração de políticas nacionais, como supõe o MSI, é mais forte entre os políticos que apóiam o presidente. Por outro lado, os deputados da oposição têm na possibilidade de marcar posição perante seu eleitorado um incentivo para propor leis de impacto nacional. Esses resultados não são inconsistentes com a essência do MSI, mas exigem certas qualificações do modelo.

\section{QUEM CONSEGUE APROVAR PROJETOS NA CÂMARA DOS DEPUTADOS?}

Afirmamos na segunda seção que a produção legislativa dos deputados não é afetada pelos partidos, no sentido de que ser filiado a umas quantas legendas partidárias não aumenta a probabilidade de que eles consigam aprovar seus projetos. Em outras palavras, não há no Brasil nenhum partido ou grupo de partidos que detenha um poder de cartel sobre a agenda legislativa, como é o caso do partido majoritário no Congresso dos Estados Unidos (Cox e McCubbins, 1993) ou dos partidos governistas em Honduras (Taylor-Robinson e Diaz, 1999), no que diz respeito a projetos de lei de autoria de deputados. Esse resultado é certamente compatível com o MSI, porque o modelo postula expressamente uma concepção não partidária do processo decisório. Na realidade, o MSI inclui uma visão distributivista desse processo, isto é, as maiorias formam-se pela troca de favores ou permuta de votos entre legisladores de orientação paroquialista, conforme sugere o estudo de Weingast e Marshall (1988). Dito de outra forma, se as coalizões partidárias não são mecanismos de articulação de maiorias no Brasil, só resta apelar para acordos de permuta de votos entre parlamentares. 
Se o partido não altera a probabilidade de um deputado conseguir aprovar seu projeto, cabe buscar nos atributos pessoais de cada um os fatores que determinam tal probabilidade. Nossas hipóteses baseiam-se em uma proposição simples: os deputados que conseguem aprovar seus projetos são os que têm a motivação e os recursos políticos necessários para tal. Não é difícil entender por que o acesso a recursos é necessário para fazer aprovar um projeto. Afinal de contas, a aprovação demanda a árdua tarefa de convencer uma maioria de parlamentares, além da superação dos obstáculos burocráticos e legais impostos pela Constituição e pelo Regimento Interno da Câmara. Desse modo, os deputados que dispõem de mais recursos devem ter maior probabilidade de obter a aprovação dos seus projetos do que os que contam com menos recursos.

Entretanto, não é óbvio que haja uma variação semelhante na motivação para propor projetos e no desejo de tê-los aprovados. Afinal, apresentar propostas de lei é uma das atividades essenciais dos deputados, de modo que todos deveriam ter o mesmo desejo de enriquecer seus currículos com a promulgação de uma lei de sua autoria. Cabe lembrar, porém, que o estudo de Power já mencionado demonstra que os antigos membros da Arena/PDS são menos operantes nas atividades parlamentares clássicas (Power, 2000:166-170). Se isto for verdade, pode-se inferir que:

Hipótese 4. A motivação para propor projetos de lei entre os deputados que eram ou tinham sido filiados à Arena/PDS é mais fraca e por isso eles têm menor probabilidade de conseguir aprová-los do que os outros parlamentares.

Examinemos agora a definição dos recursos que os deputados devem possuir para obter a aprovação dos seus projetos.

Um primeiro recurso essencial é a longevidade de suas carreiras na Câmara Federal. Quanto mais tempo de Câmara eles têm, mais tempo terão acumulado para: (a) acompanhar a tramitação de seus projetos; (b) familiarizar-se com as normas formais e informais do processo legislativo; (c) especializar-se em uma área de política pública; (d) conhecer as preferências de outros deputados e partidos; (e) aprender a fazer acordos com os colegas; (f) adquirir prestígio e, portanto, influência sobre seus pares. Portanto:

Hipótese 5. Quanto mais longa é a carreira do deputado, maior é sua probabilidade de conseguir a aprovação de um projeto. 
Outro importante recurso é o peso eleitoral. Existe na Câmara uma convenção não escrita segundo a qual os deputados de maior peso eleitoral são objeto de maior deferência ${ }^{9}$. Todos os deputados, no fim das contas, devem sua presença na Câmara aos votos que recebem e, por isso mesmo, não surpreende que seu peso eleitoral se traduza em influência política. Portanto:

Hipótese 6. Quanto maior é o peso eleitoral de um deputado, melhores são suas chances de conseguir a aprovação de um projeto.

Além desses dois recursos, consideramos que ocupar um posto na estrutura de poder da Câmara também é uma prova da influência de um deputado. O cargo proporciona a seu ocupante recursos que podem ser negociados em troca do apoio dos pares aos projetos de lei que ele encaminhou. Espera-se que essa variável capte o padrão de permuta de votos no processo decisório presumido pelo MSI. Em outras palavras:

Hipótese 7. Ocupar um posto na estrutura de poder da Câmara deve estar positivamente associado à probabilidade de obter a aprovação de um projeto.

Por fim, considerando a baixa qualidade da assessoria da Câmara, supomos que os deputados que exercem cargos na esfera executiva, sejam eleitos ou por nomeação, dispõem de um recurso escasso, qual seja, conhecimentos específicos em questões de políticas públicas que são evidentemente de grande importância para o processo legislativo. Ocupar por certo período um cargo no Executivo, seja na esfera local, estadual ou federal, proporciona a um político uma experiência inigualável que obviamente poderá traduzir-se em influência na arena parlamentar. Isso nos leva à hipótese de que:

Hipótese 8. Uma experiência prévia na esfera executiva está positivamente associada à capacidade do deputado de obter a aprovação de um projeto de lei.

\section{O Teste das Hipóteses 4 a 8}

Para verificar a validade empírica dessas cinco hipóteses, usamos novamente uma análise logit multivariada. A variável dependente é binária e avalia, para cada deputado eleito em 1982, 1986, 1990 e 1994, se ele conseguiu fazer com que pelo menos um dos seus projetos fosse transformado em lei nas legislaturas do período de 1985 a 1998. Por exemplo, um deputado que se elegeu três vezes e aprovou duas leis 
em legislaturas diferentes aparecerá três vezes na amostra. Nas duas legislaturas em que ele conseguiu aprovar uma lei, receberá o valor 1. Na legislatura em que ele não aprovou nenhuma lei, receberá o valor zero. Nossa amostra tem 2.024 observações $^{10}$. Do total de deputados que compõem a amostra, somente 171 conseguiram abrilhantar seus currículos com pelo menos uma lei sancionada entre 1985 e 1998. Ou seja, a probabilidade média de obter a aprovação de uma lei é de apenas $8,4 \%$.

Quanto às variáveis independentes, cabe lembrar o efeito da filiação prévia à Arena $/ \mathrm{PDS}^{11}$. A duração da carreira de um deputado corresponde ao número de anos que ele serviu na Câmara dos Deputados no começo de uma nova legislatura. Assim, se um deputado foi eleito pela primeira vez em 1982 e reelegeu-se em 1986, 1990 e 1994, ele aparecerá quatro vezes na amostra. Na primeira legislatura (1983-1986), a duração de sua carreira é zero; na segunda legislatura (1987-1990), é de quatro anos; na terceira (1991-1994), oito anos, e na quarta (1995-1998), doze anos.

O peso eleitoral de um deputado corresponde simplesmente ao número de votos que recebeu na última eleição. Como os distritos eleitorais no Brasil têm tamanhos e eleitorados diferentes, os deputados provenientes de distritos maiores tendem a ter mais peso eleitoral do que os que vêm de distritos menores.

Relativamente aos cargos parlamentares, atribuímos o valor 1 aos deputados que eram ou tinham sido membros da Mesa da Câmara dos Deputados, bem como aos que eram ou tinham sido líderes de partidos ou presidentes de comissões; caso contrário, atribuímos o valor zero. Finalmente, criamos uma variável binária para medir os cargos ocupados na esfera executiva. Os deputados que exerceram cargos executivos, eletivos ou por nomeação, em qualquer nível de governo, receberam o valor 1 ; caso contrário, receberam o valor zero.

A Tabela 10 informa sobre as estimativas logit. No modelo 7 , todas as variáveis saíram com o sinal esperado. O peso eleitoral foi a única variável que não obteve significância. Por isso, a excluímos do oitavo modelo $^{12}$. Neste modelo, todas as variáveis tiveram o sinal correto e foram estatisticamente diferentes de zero: filiação à Arena/PDS, duração da carreira e exercício de postos parlamentares foram signifi- 
cantes no nível de 0,01 ; o nível de significância de ter ocupado cargos executivos foi de 0,05 .

\section{Tabela 10}

Estimativas Logit da Capacidade dos Deputados de Conseguir a Aprovação de uma Lei de sua Autoria - 1985-1998 (erros padrões entre parênteses)

\begin{tabular}{l|cc}
\multicolumn{2}{c}{$\begin{array}{c}\text { As equações estimam a probabilidade de um deputado conseguir aprovar pelo } \\
\text { menos uma lei de sua autoria por legislatura }\end{array}$} \\
\hline \multirow{2}{*}{ Variáveis Independentes } & \multicolumn{2}{c}{ Modelos } \\
\cline { 2 - 3 } Constante & $-2,766^{* * *}$ & $-2,706^{* * *}$ \\
& $(, 156)$ & $(, 138)$ \\
Afiliação à Arena/PDS &,$- 530^{* * *}$ &,$- 540^{* * *}$ \\
& $(, 193)$ & $(, 193)$ \\
Duração da carreira &, $046^{* * *}$ &, $048^{* * *}$ \\
Peso eleitoral & $(, 014)$ & $(, 014)$ \\
&, 00000129 & \\
Postos parlamentares & $(, 00000154)$ & $(, 164)$ \\
&, $483^{* * *}$ &, $343^{* *}$ \\
Cargos executivos & $(, 164)$ & $(, 171)$ \\
&, $333^{*}$ & $-571,814$ \\
Log da probabilidade & $(, 171)$ & 2.024 \\
№ de observações & $-571,488$ & 2.024 \\
\hline
\end{tabular}

*** $\rho<0,01 ; * * \rho<0,05 ;{ }^{*} \rho<0,1$.

Fixando em suas médias as variáveis duração da carreira, postos parlamentares e cargos executivos, a probabilidade de um deputado que era ou foi filiado à Arena/PDS fazer aprovar uma lei é de 5,6\%; este valor sobe para 9,3\% no caso de deputados que nunca pertenceram à bancada daqueles partidos. Usando o mesmo procedimento para a duração da carreira, obtemos as probabilidades associadas a diferentes valores dessa variável, como pode ser verificado no Gráfico 1. Um deputado recém-chegado à Câmara dos Deputados tem uma probabilidade de 6,7\% de obter a aprovação de uma lei; com quatro anos de carreira, a probabilidade sobe para $8,1 \%$; com oito anos, passa para 9,6\%; e com doze anos alcança $11,4 \%$. 


\section{Gráfico 1}

Probabilidade de um Deputado Ter uma Lei Aprovada de Acordo com a Duração de sua Carreira Parlamentar

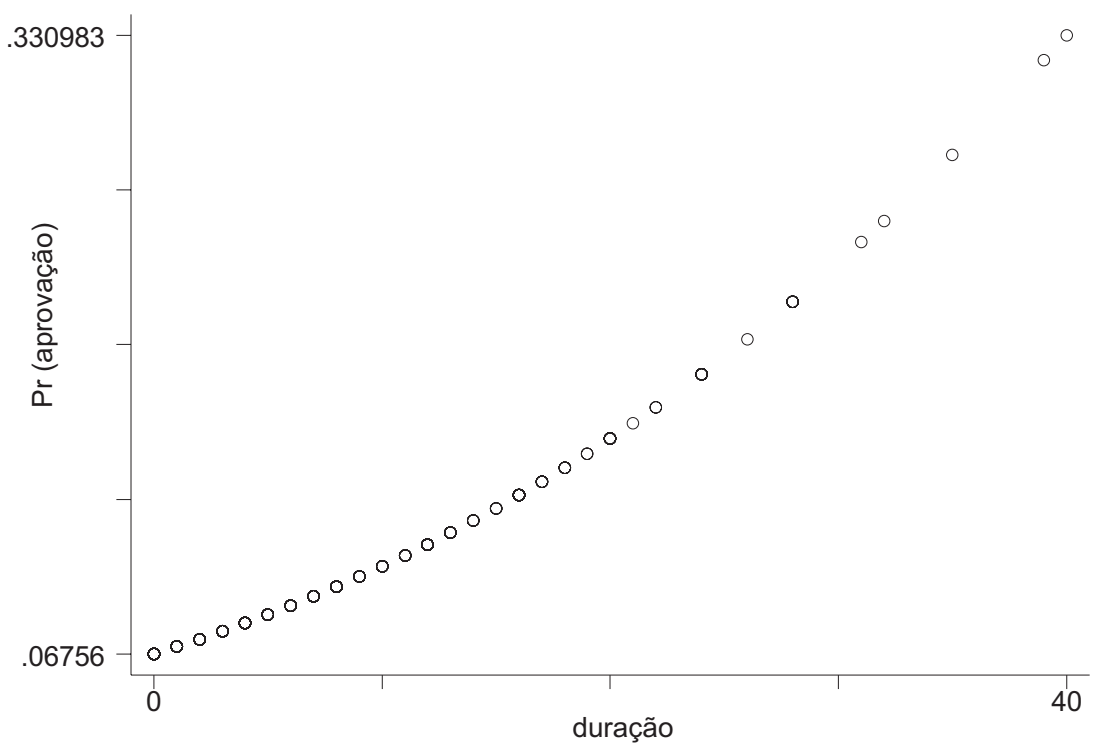

Os deputados que ocupam ou ocuparam cargos parlamentares têm 10,6\% de chances de conseguir a aprovação de uma lei, ao passo que os que não exercem ou nunca exerceram funções comparáveis têm $8,6 \%$ de possibilidades de fazê-lo. A probabilidade de fazer aprovar uma lei no caso de deputados que têm ou tiveram cargos executivos é de $9,9 \%$ contra $7,2 \%$ dos que nunca ocuparam posições semelhantes. Considerando que a probabilidade média de um deputado conseguir aprovar seu projeto é de apenas $8,4 \%$, uma diferença de $4,0 \%$ associada a um atributo individual representa quase a metade da chance média. Isto é, dada a baixa probabilidade média de um deputado conseguir a a provação de seu projeto, acreditamos que variações entre 2,0\% e 4,0\% associadas a qualidades pessoais dos parlamentares são politicamente significativas.

Falta examinar por que o peso eleitoral não afeta de modo significativo as chances de os deputados aprovarem uma lei. Uma possível explicação é que os deputados "puxadores de voto", justamente porque têm grande sucesso eleitoral, tendem a concorrer a cargos de maior 
relevo, como os de prefeito, senador e governador. E por isso mesmo, não permanecem muito tempo na Câmara. Este é um exemplo do que Samuels (2000:483) denominou de "ambição extraparlamentar", cuja lógica supõe que a maior parte dos "pesos pesados" deixe a Câmara para concorrer a postos de mais prestígio.

Por paradoxal que seja, um bom desempenho nas eleições para a Câmara dos Deputados não incentiva os políticos a nela permanecerem. Como a duração da carreira na Câmara Baixa é um fator crucial para a capacidade de um deputado aprovar seus projetos, os pesos pesados geralmente não ficam na Câmara tempo suficiente para acompanhar a tramitação dos seus projetos até a aprovação final. É por isso que o peso eleitoral não altera de modo significativo a capacidade dos deputados de obter a aprovação de suas propostas legislativas.

Que tipo de relação nossos resultados permitem estabelecer entre os determinantes da produção legislativa dos deputados e o MSI? Lembremos, antes de tudo, que este modelo contém, por definição, uma concepção não partidária do processo decisório entre Executivo e Legislativo, o que permite interpretá-lo como uma concepção distributivista na linha do que descreveram Weingast e Marshall (1988). Portanto, o fato de os partidos não influírem na produção legislativa confirma os fundamentos do modelo. Se o MSI propõe uma visão distributivista da organização parlamentar, deveríamos esperar que as decisões políticas dos deputados brasileiros resultassem da troca de favores entre eles. $\mathrm{O}$ fato de a variável que identifica se os deputados já exerceram ou não um cargo na estrutura de poder da Câmara influir significantemente na probabilidade de eles obterem a aprovação de uma lei é uma prova da presença de um importante componente distributivista na atividade legislativa desses parlamentares. O que explica essa relação é que, por ocupar um cargo na Câmara, o político tem acesso a recursos que poderá negociar com os colegas em troca de votos para os projetos que ele apresentou. Isto lembra muito a lógica do logrolling (troca de favores) elaborada por Weingast e Marshall (1988). Contudo, os efeitos da permuta de votos entre deputados brasileiros - as leis efetivamente sancionadas - não se prestam, de modo geral, a fins locais. A razão disso é que, conforme observamos na segunda seção, o poder do Congresso para iniciar leis de natureza orçamentária e fiscal é muito limitado. 


\section{DISCUSSÃO}

O que nos dizem os resultados desta pesquisa sobre o modelo do segredo ineficiente proposto por Shugart e Carey? Em primeiro lugar, o fato de a maior parte da produção legislativa dos deputados brasileiros não ter em vista problemas locais não contradiz o modelo. A explicação disto está nas barreiras constitucionais que impedem os deputados federais de propor leis envolvendo a transferência de recursos para regiões e clientelas restritas. É este justamente o "passo atrás" subjacente a um desenho institucional baseado no segredo ineficiente. E a conseqüência é que os deputados investem seu tempo e os poucos recursos de que dispõem para atividades legislativas em questões tópicas de política social de abrangência nacional.

Em segundo lugar, o MSI tem uma grave deficiência: a incapacidade de modelar adequadamente o papel dos partidos e da oposição. Existe, sem dúvida, um incentivo para delegar ao Executivo a formulação de políticas públicas de alcance nacional, mas esse incentivo repercute com mais força nos políticos que apóiam o governo. Os partidos de oposição usam suas prerrogativas de introduzir projetos de lei de abrangência nacional para fazer propaganda de suas posições políticas perante os eleitores e com isso fortalecer suas chances de chegar à Presidência da República. Se esta tese estiver correta, então é possível que no interior de um sistema baseado no segredo ineficiente se gere de maneira endógena uma dinâmica eleitoral mais eficiente. É essa possibilidade que o Partido dos Trabalhadores tem exemplificado no Brasil. Fazendo uma oposição sistemática aos governos com base em propostas políticas de abrangência nacional, o PT tornou-se um dos principais competidores na corrida à Presidência da República. E, desde as primeiras eleições pluripartidárias livres de 1982, a representação do PT no Congresso tem tido um crescimento constante, a ponto de tornar-se o maior partido da Câmara dos Deputados depois das eleições de outubro de 2002.

A bem da verdade, uma das principais dificuldades das análises institucionalistas centradas nos incentivos eleitorais gerados pelo sistema de representação proporcional de lista aberta sempre foi a de explicar a alta disciplina em plenário dos membros do PT. Este fato foi em parte elucidado pelo estudo de Barry Ames a respeito da competição eleitoral no Brasil, em que ele mostrou que a principal característica do sistema de representação proporcional de lista aberta em grandes dis- 
tritos de mais de um representante não é a de favorecer o voto pessoal, mas a de facilitar a multiplicação de estratégias eleitorais. É bem verdade que algumas dessas estratégias realmente estimulam um foco estreito de atuação parlamentar previsto pelo MSI. E já vimos que estas são as que favorecem o paroquialismo na proposição de leis. Há, no entanto, outras estratégias que estimulam uma visão mais ampla. É significativo que o PT tenha sido o partido que mais investiu no conteúdo informativo de sua legenda (Samuels, 1999), estratégia que se tem revelado bem-sucedida mesmo nos confins de um sistema baseado no segredo ineficiente.

O MSI oferece uma visão demasiado atomística ou não partidária do processo político. Um óbvio corolário disto é o fato de o Brasil ser, de maneira geral, governado por coalizões ad hoc. O modelo simplesmente não leva em consideração a possibilidade de que os presidentes e os partidos eventualmente se unam para compor maiorias de governo estáveis. Quando são formadas, essas maiorias podem oferecer aos eleitores importantes informações acerca de quem deve ser cobrado pelas políticas públicas nacionais em eleições congressuais, contribuindo para elevar o nível de eficiência eleitoral. De fato, muitos estudos mostram que Fernando Henrique Cardoso contou com uma coalizão governista mais estável do que outros presidentes (Amorim Neto, 2002; Amorim Neto et alii, 2003; Figueiredo e Limongi, 1999; Mainwaring, 1999:313-317; Nicolau, 2000). Isto é, o modelo do segredo ineficiente descarta muito radicalmente os partidos, o que prejudica seriamente sua capacidade de explicar a dinâmica eleitoral e o processo decisório no Brasil e em outros países da América Latina.

O fato de termos introduzido no modelo, em mais alto grau, as clivagens e coalizões partidárias levou-nos à conclusão de que os sistemas políticos baseados no segredo ineficiente podem ter às vezes eleições congressuais muito ineficientes, porque o comportamento dos parlamentares não oferece aos eleitores escolhas claramente identificáveis de políticas nacionais. Mas isso só acontece quando o Executivo se apóia exclusivamente em coalizões ad hoc. Sempre que o Executivo tem o apoio de uma coalizão estável, as eleições congressuais podem alcançar níveis significativamente mais elevados de eficiência eleitoral.

Nossa análise sobre quem consegue aprovar seus projetos mostra que o Congresso brasileiro tem um papel de menor importância no pro- 
cesso legislativo não só por causa das restrições impostas pelo segredo ineficiente - isto é, a ampla delegação ao Executivo da autoridade para tomar decisões sobre políticas públicas de abrangência nacional - , mas também em virtude dos incentivos à construção das carreiras parlamentares. A essência desses incentivos é que o Poder Executivo é o locus fundamental da influência política, o que dissuade os deputados de tentarem construir uma carreira mais duradoura no Congresso. A falta de políticos dispostos a permanecer muito tempo no Congresso enfraquece ainda mais o papel do Legislativo na formulação de políticas nacionais. Em síntese, os fracos incentivos à construção de longas carreiras parlamentares contribuem para reforçar alguns aspectos da lógica que está na base do modelo do segredo ineficiente.

Finalmente, nossa análise empírica indica que os partidos não afetam o que os deputados aprovam e que há um importante aspecto distributivista na capacidade dos deputados brasileiros de aprovarem leis, conforme evidencia a significância estatística da variável explicativa que identifica quem exerceu ou não cargos burocráticos na Câmara. Portanto, se há uma influência partidária no que os deputados propõem, outros fatores determinam o que eles aprovam. Essa diferença entre os determinantes do que é proposto e do que é aprovado se explica pelo fato de que a legislação apresentada por deputados que tramita com sucesso na Câmara tende a situar-se fora da dimensão dominante do conflito partidário. Isto transforma os deputados - principalmente os dos partidos de oposição - em patrocinadores de temas que passam ao largo da dimensão política dominante e em agentes potenciais do realinhamento de partidos e alianças ${ }^{13}$.

Em suma, dada a complexidade empírica dos dados apresentados neste artigo, acreditamos que futuros trabalhos deveriam considerar seriamente a sugestão de que a melhor forma de construir modelos sobre o comportamento dos parlamentares e o processo decisório nos regimes presidencialistas do Brasil e de outros países da América Latina que se baseiam no segredo ineficiente é incorporar e combinar fatores partidários e distributivistas. Um modelo que desconsidere quaisquer desses aspectos se arrisca a oferecer uma visão demasiado restritiva da realidade política.

(Recebido para publicação em novembro de 2003) (Versão definitiva em dezembro de 2003) 


\section{NOTAS}

1. Essa proposição não é diretamente dedutível do MSI, mas pode ser derivada da hipótese contida no modelo de que a agenda legislativa é dominada pelo Executivo, o que significa que haverá menos tempo para o exame dos projetos de lei dos congressistas.

2. Agradecemos a Antônio Octávio Cintra por nos ter alertado sobre essas limitações de nossa classificação.

3. Agradecemos a Fernando Limongi por nos ter chamado a atenção para este ponto.

4. Não estamos dizendo que o Executivo inglês deixou de tratar dos problemas sociais. A história da Inglaterra no século XX mostra que os gabinetes chefiados por líderes liberais (Herbert H. Asquith, 1908-1951 e David Lloyd George, 1916-1922), assim como os trabalhistas (Ramsay MacDonald, 1929-1935 e Clement Attlee, 1945-1951), foram responsáveis pela parcela mais importante da legislação social inglesa.

5. Os dados sobre filiação à Arena / PDS na legislatura de 1995-1998 foram obtidos em Brasil. Câmara dos Deputados (1995).

6. Quando usamos o número de projetos paroquiais-benéficos, em vez de uma variável binária, como indicador operacional da variável dependente, os resultados são iguais do ponto de vista da significância estatística e do sinal das variáveis independentes. Como o número de projetos paroquiais-benéficos somente pode assumir valores inteiros não-negativos, o modelo binomial negativo é o método apropriado de análise econométrica, conforme recomenda King (1998). Esse modelo produz os seguintes resultados substantivos: um deputado com uma concentração geográfica máxima de votos tinha uma probabilidade de $18,0 \%$ de iniciar pelo menos um projeto paroquial-benéfico em comparação com a probabilidade de 5,4\% de um deputado com dispersão máxima de votos - uma diferença ligeiramente menor que a gerada pelo modelo logit.

7. Os partidos representados no Ministério em 1995 eram o PSDB, PFL, PMDB e o PTB (Amorim Neto, 2002:56).

8. Novamente, quando usamos o número de projetos de lei de alcance nacional como variável dependente e adotamos o modelo binomial negativo como nosso modelo econométrico, os resultados qualitativos são os mesmos gerados pela análise logit. No entanto, as diferenças entre as probabilidades são muito maiores no caso da dominância e um pouco menores no caso da participação no governo. Fixando na média a participação na coalizão parlamentar do presidente, descobrimos que um deputado com dominância máxima tem uma probabilidade de 35,5\% de propor pelo menos um projeto de alcance nacional, enquanto um deputado com dominância mínima possui uma chance de $92,6 \%$ de encaminhar pelo menos um projeto de lei de nível nacional, uma diferença de 57,1\%! Fixando a dominância em sua média, descobrimos que um deputado que apóia o governo tem uma probabilidade de $75,9 \%$ de propor pelo menos um projeto de nível nacional contra a probabilidade de $87,1 \%$ de um deputado da oposição tomar igual iniciativa.

9. Agradecemos a Nelson Carvalho, assessor parlamentar do Congresso, por nos ter alertado para essa convenção. 


\section{Octavio Amorim Neto e Fabiano Santos}

10. Note-se, porém, que o número de deputados eleitos em 1982, 1986, 1990 e 1994, 2.292, é superior ao da amostra, 2.024. Infelizmente, não conseguimos obter informações completas sobre todos os deputados.

11. Os dados sobre a filiação à Arena / PDS no período 1985-1994 nos foram fornecidos por Timothy Power (2000). Para a legislatura de 1995-1998, os dados provêm de Brasil. Câmara dos Deputados (1995).

12. O peso eleitoral também foi operacionalizado como o número de votos recebidos por um deputado dividido pela cota eleitoral do distrito do deputado. Essa medida também não se revelou significante.

13. Agradecemos a John Carey por nos ter chamado a atenção para essa possibilidade.

\section{REFERÊNCIAS BIBLIOGRÁFICAS}

AMES, Barry. (1995), “Electoral Rules, Constituency Pressures, and Pork Barrel: Bases of Voting in the Brazilian Congress". The Journal of Politics, n- 57, pp. 324-343. . (2001), The Deadlock of Democracy in Brazil: Interests, Identities, and Institutions in Comparative Perspective. Ann Arbor, University of Michigan Press.

AMORIM NETO, Octavio. (2002), "Presidential Cabinets, Electoral Cycles, and Coalition Discipline in Brazil", in S. Morgenstern e B. Nacif (orgs.), Legislative Politics in Latin America. New York, Cambridge University Press.

— , COX, Gary W. e MCCUBBINS, Matthew D. (2003), "Agenda Power in Brazil's Câmara dos Deputados". World Politics, vol. 55, no 4, pp. 550-578.

BRASIL. CÂMARA DOS DEPUTADOS. (1995), Deputados Brasileiros: Repertório Biográfico, 50ª Legislatura, 1995-1999. Brasília, Câmara dos Deputados, Coordenação de Publicações.

BRASIL. SENADO FEDERAL. (2000), 500 Anos de Legislação Brasileira (CD-ROM). Brasília, PRODASEN.

CAREY, John M. e SHUGART, Matthew S. (1995), “Incentives to Cultivate a Personal Vote: A Rank Ordering of Electoral Formulas". Electoral Studies, vol. 14, pp. 417-439.

_ (orgs.). (1998), Executive Decree Authority. New York, Cambridge University Press.

COX, Gary W. (1987), The Efficient Secret: The Cabinet and the Development of Political Parties in Victorian England. Cambridge, MA, Cambridge University Press.

e MCCUBBINS, Matthew D. (1993), Legislative Leviathan: Party Government in the House. Berkeley, University of California Press.

ELSTER, Jon. (1988), Ulysses and the Sirens: Studies in Rationality and Irrationality. New York, Cambridge University Press. 
FIGUEIREDO, Argelina C. e LIMONGI, Fernando. (1999), Executivo e Legislativo na Nova Ordem Constitucional. Rio de Janeiro, Fundação Getulio Vargas Editora.

_. (2000), "Presidential Power, Legislative Organization, and Party Behavior in Brazil". Comparative Politics, no 32, pp. 151-170.

JONES, Mark P. (1995), Electoral Laws and the Survival of Presidential Democracies. Notre Dame, University of Notre Dame Press.

KING, Gary. (1998), Unifying Political Methodology: The Likelihood Theory of Statistical Inference. Ann Arbor, University of Michigan Press.

LEMOS, Leany Barreiro de S. (2001), “O Congresso Brasileiro e a Distribuição de Benefícios Sociais no Período 1988-1994: Uma Análise Distributivista". Dados, vol. 44, nํㅡㄴ 3, pp. 561-605.

LIJPHART, Arend. (1999), Patterns of Democracy: Government Forms and Performance in Thirty-Six Countries. New Haven, Yale University Press.

LIMONGI, Fernando e FIGUEIREDO, Argelina C. (1995), “Partidos Políticos na Câmara dos Deputados: 1989-1994". Dados, vol. 38, nㅇ3, pp. 497-524.

_. (2001a), “Em Busca do Orçamento Perdido: Primeiros Rugidos". Inteligência, no 14, pp. 64-72.

. (2001b), “Em Busca do Orçamento Perdido II: O Fisiologismo, se Subiu, Ninguém Viu". Inteligência, no 15 , pp. 58-72.

LINZ, Juan J. e VALENZUELA, Arturo (orgs.). (1994), The Failure of Presidential Democracies: The Case of Latin America (vol. 2). Baltimore, The Johns Hopkins University Press.

MAINWARING, Scott P. (1999), Rethinking Party Systems in the Third Wave of Democratization: The Case of Brazil. Stanford, Stanford University Press.

_ e SCULLY, Timothy R. (orgs.). (1995), Building Democratic Institutions: Party Systems in Latin America. Stanford, Stanford University Press.

MAINWARING, Scott P. e SHUGART, Matthew S. (orgs.). (1997), Presidentialism and Democracy in Latin America. New York, Cambridge University Press.

MARSH, David e READ, Melvin. (1988), Private Members' Bills. Cambridge, Cambridge University Press.

MORGENSTERN, Scott e NACIF, Benito (orgs.). (2002), Legislative Politics in Latin America. New York, Cambridge University Press.

MÜLLER, Wolfgang e STRØM, Kaare (orgs.). (1999), Policy, Office, or Votes: How Political Parties in Western Europe Make Hard Decisions. Cambridge, Cambridge University Press.

NICOLAU, Jairo. (2000), “Disciplina Partidária e Base Parlamentar na Câmara dos Deputados no Primeiro Governo de Fernando Henrique Cardoso (1995-1998)". Dados, vol. 43, no 4, pp. 709-734.

POWER, Timothy J. (2000), The Political Right in Postauthoritarian Brazil: Elites, Institutions, and Democratization. University Park, PA, The Pennsylvania State University Press. 


\section{Octavio Amorim Neto e Fabiano Santos}

SAMUELS, David J. (1999), "Incentives to Cultivate a Party Vote in Candidate-Centric Electoral Systems: Evidence from Brazil". Comparative Political Studies, no 32, pp. 487-518.

. (2000), "Ambition and Competition: Explaining Legislative Turnover in Brazil". Legislative Studies Quarterly, no 25, pp. 481-497.

. (2002), "Progressive Ambition, Federalism, and Pork-Barreling in Brazil", in S. Morgenstern e B. Nacif (orgs.), Legislative Politics in Latin America. New York, Cambridge University Pres.

SHUGART, Matthew S. e CAREY, John M. (1992), Presidents and Assemblies: Constitutional Design and Electoral Dynamics. Cambridge, Cambridge University Press.

STRØM, Kaare. (1990), “A Behavioral Theory of Competitive Political Parties”. American Journal of Political Science, n- 34, pp. 565-598.

TAYLOR-ROBINSON, Michelle M. e DIAZ, Cristopher. (1999), “Who Gets Legislation Passed in a Marginal Legislature and Is the Label Marginal Legislature Still Appropriate? AStudy of the Honduran Congress". Comparative Political Studies, n-32, pp. 589-625.

WEINGAST, Barry e MARSHALL, William J. (1988), “The Industrial Organization of Congress; or Why Legislatures, Like Firms, Are Not Organized as Markets". Journal of Political Economy, no 96, pp. 132-163. 


\section{GLOSSÁRIO}

Arena - Aliança Renovadora Nacional

PCB - Partido Comunista Brasileiro

PC do B - Partido Comunista do Brasil

PDC - Partido Democrata Cristão

PDS - Partido Democrático Social

PDT - Partido Democrático Trabalhista

PFL - Partido da Frente Liberal

PJ - Partido da Juventude

PL - Partido Liberal

PMDB - Partido do Movimento Democrático Brasileiro

PPB - Partido Popular Brasileiro

PPR - Partido Progressista Renovador

PPS - Partido Popular Socialista

PRN - Partido da Reconstrução Nacional

PSB - Partido Socialista Brasileiro

PSDB - Partido da Social Democracia Brasileira

PT - Partido dos Trabalhadores

PTB - Partido Trabalhista Brasileiro 


\section{ABSTRACT \\ The Inefficient Secret Revisited: The Legislative Input and Output of Brazilian Deputies}

Shugart and Carey posit that presidential democracies in which legislators have a parochial focus of representation are electorally inefficient because voters are not offered highly identifiable choices on national policies. Such systems are driven by an inefficient secret, which is essentially a nonpartisan representation of the policy process. To check the propositions of the inefficient secret model (ISM), this article investigates the aggregation level, effect, and subject of Brazilian deputies' legislative input and output. Our empirical analysis indicates that, although some ISM-related factors drive legislative output, there is partisanship in deputies' legislative input. This result means that the ISM underestimates the prospects for programmatic parties (especially in the opposition) to emerge within systems where the electoral and constitutional rules encourage particularism.

Key words: legislative output; Brazilian Congress; inefficient secret

\section{RÉSUMÉ}

Le Réexamen d'un Secret Inefficace: Ce que Proposent les Députés Brésiliens et ce qu'ils Sanctionnent

Shugart et Carey croient que les démocraties présidentielles où les législateurs ont une conception restreinte de la représentation politique sont inefficaces d'un point de vue électoral car elles n'offrent pas aux électeurs de possibilités de choix faciles à reconnaître parmi des politiques à l'échelon national. Ces démocraties sont régies par un secret inefficace, c'est-à-dire une conception de la dynamique politique indépendante d'un parti. Afin de vérifier les propositions du modèle du secret inefficace (MSI), on examine dans cet article le niveau de rassemblement, l'effet et les thèmes des projets et des lois approuvées par les députés brésiliens. L'analyse empirique montre que, bien qu'on trouve une certaine influence des partis dans les projets présentés par les députés, les lois sanctionnées par l'activité législative sont guidées par d'autres types de facteurs, ce qui, en partie, vient confirmer le dit modèle.

Mots-clé: production législative; Congrès national; secret inefficace 